\title{
Ameliorative effect of bee venom and its extracted bradykinin-potentiating factor on neurological alteration induced by acrylamide and chips administration
}

Fakhr El-Din M. Lashein*, El-Sabry Abu Amra, Amin A. Seleem and Amira H. Badr

\begin{abstract}
Background: Acrylamide is reported for its toxicity on the central and the peripheral nervous system and causes paralysis. Bee venom (BV) and bradykinin-potentiating factor (BPF) have been documented for their potential therapeutic effects as anti-neuroinflammation. The study aimed to ameliorate the neurotoxic effects of acrylamide or chips by using BV or its extracted BPF. Mice were divided into 15 subgroups: control (G1.1, G1.2, G1.3) at 30, 45, and 60 days, respectively; acrylamide- $(10 \mathrm{mg} / \mathrm{kg}$ b.w.; orally daily) administered subgroup for 30 days (G2.1), 45 days (G2.2), and 60 days (G2.3); chips feeding group (1/3 of daily diet) for 30 days (G3.1), 45 days (G3.2), and 60 days (G3.3); bee venom-treated group for 60 days (1.319 mg/kg b.w.) (G4.1); BPF-treated group for 60 days (2.314 mg/kg b.w.) (G4.2), day after the other day; and acrylamide- or chips-administered groups combined either with BV $(G 5.1, G 6.1)$ or BPF treatment $(G 5.2, G 6.2)$ for 60 days.

Results: The results indicated that the approximate LD50 for BV and BPF equal to $13.19 \mathrm{mg} / \mathrm{kg}$ and $23.14 \mathrm{mg} / \mathrm{kg}$, respectively, and the extracted BPF contains 15 amino acids. Also, the results showed abnormal gait in mice of acrylamide-administered groups which was accompanied by histopathological changes in the hippocampus, cerebellum, and cerebral cortex. A marked gradual increase of alpha-synuclein expression was noted at the studied region in the acrylamide- and chips-treated groups at 60 days of treatment as compared to control. Both BV- and BPF-treated groups either separately or in co-administration with acrylamide or with chips did not show any histopathological changes in the studied regions with downregulated expression of alpha-synuclein.
\end{abstract}

Conclusion: The study concluded the neuroprotective effect of BV and its extracted BPF against neurotoxicity induced by acrylamide or chips administration.

Keywords: Acrylamide, Bee venom (BV), Bradykinin-potentiating factor (BPF), Brain disorder, Neurotoxicity

\section{Background}

Acrylamide is a white crystalline solid, non-volatile, odorless, and has a high mobility in soil and groundwater (Ashoor \& Zent, 1984; Eriksson, 2005). The common uses of acrylamide are in papermaking aids, dyes, cosmetics, production of polyacrylamides, flocculants in sewage and wastewater treatment, enhancers of oil recovery, ore processing, clarifying drinking water, and grouting agents for the construction of dam foundations (Smith \& Oehme, 1991). Acrylamide is formed during heat processing of carbohydrate-rich foods at elevated

\footnotetext{
*Correspondence: flashein@yahoo.com

Department of Zoology, Faculty of Science, Sohag University, Sohag, Egypt
}

temperatures $\left(120^{\circ} \mathrm{C}\right)$ or above (Maillard reaction) during frying, broiling, baking, roasting, grilling, and toasting (Tareke, Rydberg, Karlsson, Eriksson, \& Törnqvist, 2002) due to the natural presence of the reactants (glucose/fructose and asparagine) which are involved in the formation of acrylamide. Acrylamide is not found in foods which are not fried or baked such as boiling (Eriksson, 2005; Törnqvist, 2005). Acrylamide has been shown to be toxic to both the central and the peripheral nervous system (LoPachin, 2004; LoPachin, Schwarcz, Gaughan, Mansukhani, \& Das, 2003). Toxicological studies suggested that acrylamide causes 
paralysis of the cerebrospinal system (Johnson et al., 1986; Zhang, Zhang, \& Zhang, 2005).

Bee venom (BV) is known as apitoxin and a complex mixture of at least 18 active components, including enzymes, biogenic amines, and several biologically active peptides including melittin, apamin, mast cell degranulating peptide, adolapin, secapin, procamine, tertiapin, and cardiopep, and non-peptide components (e.g., histamine, lipids, and carbohydrates) (Chen \& Lariviere, 2010; Kwon et al., 2001; Orśolić, 2012; Son, Lee, Lee, Song, \& Lee, 2007). Bee venom contains a variety of enzyme constituents, including phospholipase A2, hyaluronidase, acid phosphatase, dipeptidylpeptidase IV, carboxylesterase, and serine carboxypeptidase (Hoffman, 2006; Kim \& Jin, 2016; Peiren et al., 2008; Son et al., 2007). Numerous studies have reported that bee venom has biological, toxicological, and pharmacological properties (Chen \& Lariviere, 2010; Ozdemir, Kucuksezer, Akdis, \& Akdis, 2011; Son et al., 2007). Moreover, it was documented as immune stimulator, and anticancer, with radioprotective and neuroprotective effects (Gajski \& Garaj-Vrhovac, 2009; Khalil, Assaf, ElShebiney, \& Salem, 2015; Orśolić, 2012; Son et al., 2007).

Bradykinin-potentiating peptides (BPPs) are peptides which purified from several organisms including invertebrates (Torfs et al., 1999), wasp venoms (Konno et al., 2002), amphibian skin secretions (Chen, Zhou, Gagliardo, Walker, \& Shaw, 2006; Conlon et al., 2005), and crustaceans (Rittschof \& Cohen, 2004). Also, BPPs were documented in snakes as Bothrops jararaca (Ferreira, 1965, Ferreira et al., 1970; Ferreira et al., 1995); scorpion, Tityus serrulatus (Ferreira, Alves, \& Henriques, 1993) and Buthus occitanus (Meki, Nassar, \& Rochat, 1995); and jelly fish venoms (Abd-El-Rahim, 1995). BPPs are peptides with hypotensive properties that have been previously described in the literature regarding venom of different animal groups (Hodgson \& Isbister, 2009; Yeow \& Kini, 2012). Also, BPP plays a major role in the regulation of peripheral blood flow and in the primary reaction of tissues to noxious stimuli (Roberts, 1989); thus, BPF has profound effects on the cardiovascular system (Hodgson \& Isbister, 2009). The aim of this study is to evaluate the neuroprotective effect of bee venom (BV) and its extract of bradykinin-potentiating factor (BPF) against acrylamide-induced neurotoxicity.

\section{Methods}

\section{Chemicals}

Acrylamide was obtained commercially from Sigma Chemical Company, St. Louis, USA. Bee venom of Apis mellifera was obtained from the Faculty of Agriculture, Assiut University, Egypt. Bradykinin-potentiating factor (BPF) was isolated from bee venom according to the chemical methods of Ferreira (1965).

\section{Experimental design and processing}

Determination of median lethal dose LD50 of the bee venom (BV) and bradykinin-potentiating factor (BPF) was carried out by intraperitoneal (i.p.) injection according to the method of Meier and Theakston (1986). The BPF extract was analyzed for its amino acid contents in the National Research Center using amino acid analyzer LC3000, Germany. Male albino mice, Mus musculus, weighing approximately $20-25 \mathrm{~g}$ were brought from the farm of the Zoology Department, Sohag University, Egypt. Animals were kept in the laboratory under normal conditions of light, temperature, and humidity with access to food and water. Animals were classified into six main groups (five mice each subgroup). The first main group (G1) was a control. The second main group (G2) was subdivided into three subgroups which were orally administered with acrylamide $(10 \mathrm{mg} / \mathrm{kg}$ b.w.) daily for 30 days (G2.1), 45 days (G2.2), and 60 days (G2.3). The third main group (G3) was subdivided into three subgroups which were fed one third of its daily diet by chips for 30 days (G3.1), 45 days (G3.2), and 60 days (G3.3). The fourth main group (G4) was subdivided into two groups which were treated i.p. with bee venom (1.319 $\mathrm{mg} / \mathrm{kg}$ b.w.) (G4.1) and BPF (2.314 mg/kg b.w.) (G4.2), respectively, day after the other day for 60 days. The fifth main group (G5) was subdivided into two groups (10 animals each) which were administered with acrylamide orally (10 mg/kg b.w.) combined either with i.p. by bee venom $(1.319 \mathrm{mg} / \mathrm{kg}$ b.w.) (G5.1) or with BPF (2.314 $\mathrm{mg} / \mathrm{kg}$ b.w.) (G5.2), respectively, day after the other day for 60 days. The sixth main group (G6) was subdivided into two groups which were fed $1 / 3$ of its daily diet by chips for 60 days combined either with i.p. by bee venom (1.319 $\mathrm{mg} / \mathrm{kg}$ b.w.) (G6.1) or with BPF (2.314 $\mathrm{mg} / \mathrm{kg}$ b.w.) (G6.2), respectively, day after the other day for 60 days. This study was approved by the Social Science Ethical Committee of the Faculty of Science, Tanta University, and complied with the Egyptian Code of Conduct for Scientific Practice, National Research Centre, Egypt.

\section{Histological and immunohistochemical}

All animals in studied groups were anesthetized, sacrificed, and dissected. The brains of the studied groups were fixed in Carnoy's fixative, dehydrated in ethyl alcohol, cleared in methyl benzoate, and embedded in paraffin wax at $60{ }^{\circ} \mathrm{C}$ for sectioning. The sections were mounted on slides and were stained with hematoxylin and eosin for general histology (Drury \& Wallington, 1976). Sections were dehydrated in ascending grades of ethanol, cleared in xylene, and mounted with DPX. For immunostaining of $\alpha$-synuclein, $7-\mu$-thick paraffin wax sections of the brains of the studied groups were mounted on Superfrost/Plus glass slides. The slides were 
deparaffinized in xylene, rehydrated in ethanol, and retrieved for re-antigenicity using $10 \mathrm{mM}$ citrate buffer at $\mathrm{pH}=6$ in $100{ }^{\circ} \mathrm{C}$ for an hour (Buchlowalow \& Bocker, 2010). According to the manufacture protocol of the Spring Bioscience company, the sections were treated for 10 min with hydrogen peroxide block and protein block then incubated with primary antibody against $\alpha$-synuclein (Rabbit, anti-synuclein-alpha polyclonal, Spring Bioscience, Pleasanton, USA) for $3 \mathrm{~h}$ at room temperature. Sections were then washed using phosphate buffer ( $\mathrm{pH}$ 7.4) and incubated with secondary antibody (Biotinylated Goat Anti-polyvalent HRP DAB detection system, Spring Bioscience, Pleasanton, USA). $\mathrm{DAB}$ and chromogen were mixed to visualize the color of reaction. Sections were dehydrated, cleared, and mounted. Selected sections at the level of histological and immunohistochemical were photographed and processed as required.

\section{Results}

\section{Lethal dose of bee venom and bradykinin-potentiating} factor (BPF)

The approximate LD50 for bee venom and bradykinin-potentiating factor equal to $13.19 \mathrm{mg} / \mathrm{kg}$ and $23.14 \mathrm{mg} /$ kg, respectively, as shown in Tables 1 and 2 and Figs. 1 and 2 .

\section{Amino acid analysis of bradykinin-potentiating factor (BPF)}

Amino acid analysis of BPF separated from the bee venom of Apis mellifera revealed the presence of 15 amino acids: nonpolar aliphatic, aromatic, polar, negatively charged, and positively charged. The nonpolar aliphatic includes alanine, valine, leucine, isoleucine, methionine, and proline in concentrations 303.00, 111.46, 56.32, 16.04, 336.91, and $51.12 \mu \mathrm{g} / \mathrm{ml}$, respectively. Aromatic amino acids include phenylalanine and tyrosine in concentrations 20.02 and $65.40 \mu \mathrm{g} / \mathrm{ml}$, respectively. Polar amino acids include serine, histidine, and threonin in concentrations 110.51, 73.09, and $122.61 \mu \mathrm{g} / \mathrm{ml}$, respectively. Negatively charged

Table 1 LD50 determination table of bee venom

\begin{tabular}{llllll}
\hline M & Weight & $\begin{array}{l}\text { Dose } \\
(\mathrm{mg} / \mathrm{mice})\end{array}$ & $\begin{array}{l}\text { Dose } \\
(\mathrm{mg} / \mathrm{kg})\end{array}$ & $\begin{array}{l}\text { Survival } \\
\text { time }(\mathrm{min})\end{array}$ & $\begin{array}{l}\text { Dose }(\mathrm{mg} / \mathrm{kg} / \mathrm{survival} \\
\text { time) }\end{array}$ \\
\hline 1 & 26 & 3.2 & 123.076923 & 34 & 3.6199095 \\
2 & 29 & 3.6 & 124.137931 & 35 & 3.546798 \\
3 & 31 & 2.8 & 90.3225806 & 36 & 2.5089606 \\
4 & 34 & 2 & 58.8235294 & 45 & 1.3071895 \\
5 & 25.5 & 1.2 & 47.0588235 & 18 & 2.6143791 \\
6 & 25.8 & 1.8 & 69.7674419 & 40 & 1.744186 \\
7 & 26.4 & 2.4 & 90.9090909 & 35 & 2.5974026 \\
8 & 23.7 & 1.6 & 67.5105485 & 34 & 1.9856044 \\
\hline
\end{tabular}

Table 2 LD50 determination table of BPF

\begin{tabular}{llllll}
\hline M & Weight & $\begin{array}{l}\text { Dose } \\
(\mathrm{mg} / \text { mice) }\end{array}$ & $\begin{array}{l}\text { Dose } \\
(\mathrm{mg} / \mathrm{kg})\end{array}$ & $\begin{array}{l}\text { Survival } \\
\text { time }(\mathrm{min})\end{array}$ & $\mathrm{D} / \mathrm{T}$ \\
\hline 1 & 33 & 2.4 & 72.72 & 32 & 2.2725 \\
2 & 32 & 1.2 & 37.5 & 23 & 1.630435 \\
3 & 31 & 1.5 & 48.38 & 12 & 4.031667 \\
4 & 29 & 0.9 & 31.03 & 76 & 0.408289 \\
5 & 33.4 & 2 & 59.88024 & 50 & 1.197605 \\
6 & 28.9 & 0.867 & 30 & 71 & 0.422535 \\
7 & 28.9 & 0.289 & 10 & 77 & 0.12987 \\
8 & 32 & 4.5 & 140.62 & 17 & 8.271765
\end{tabular}

include glutamic and aspartic acids in concentrations 545.05 and $220.77 \mu \mathrm{g} / \mathrm{ml}$, respectively. Positively charged include lysine and arginine in concentrations 157.73 and $248.33 \mu \mathrm{g} / \mathrm{ml}$, respectively.

\section{Morphological observation}

Decreased active movement, lethargy, and abnormal gait were observed in mice of the acrylamide-administrated group for 45 days (Fig. 3c, arrows) and for 60 days (Fig. 3d, arrows). These symptoms showed an aggravating tendency as the administration period progressed. The distance between hind limbs became wider when walking. Furthermore, at 45 and 60 days from treatment, mice dragged their feet as they could not support their body (Fig. 3c, d). However, no abnormal change was observed in the control group and the group administered with acrylamide for 30 days (Fig. 3a, b). The chips-administered groups at 30,45, and 60 days did not show any abnormalities in walking (Fig. $3 \mathrm{e}-\mathrm{g}$ ). The bee venom- and BPF-treated groups at 60 days of treatment showed similar behavior that was noted in the control group (Fig. 3h, i). The acrylamide-administrated groups at 60 days treated with either bee venom or BPF showed improvement in movement and gait (Fig. 3j, k) as compared with the acrylamide-administered group for 45 and 60 days. The combined chips groups either with bee venom or with BPF treatment showed similar movement to the control (Fig. 3l, m).

\section{Histological and immunohistochemical studies Hippocampus}

Histological examination of hematoxylin and eosinstained sections of the control group revealed the characteristic areas of the hippocampus (Fig. 4A). These areas are the hippocampus proper and dentate gyrus. The hippocampus proper is formed of Cornu Ammonis that consists of various zones. CA1 and CA2 consist of small pyramidal cells while CA3 and CA4 consist of large pyramidal cells. CA4 projects into the dentate gyrus (DG). The acrylamide-administered group along 


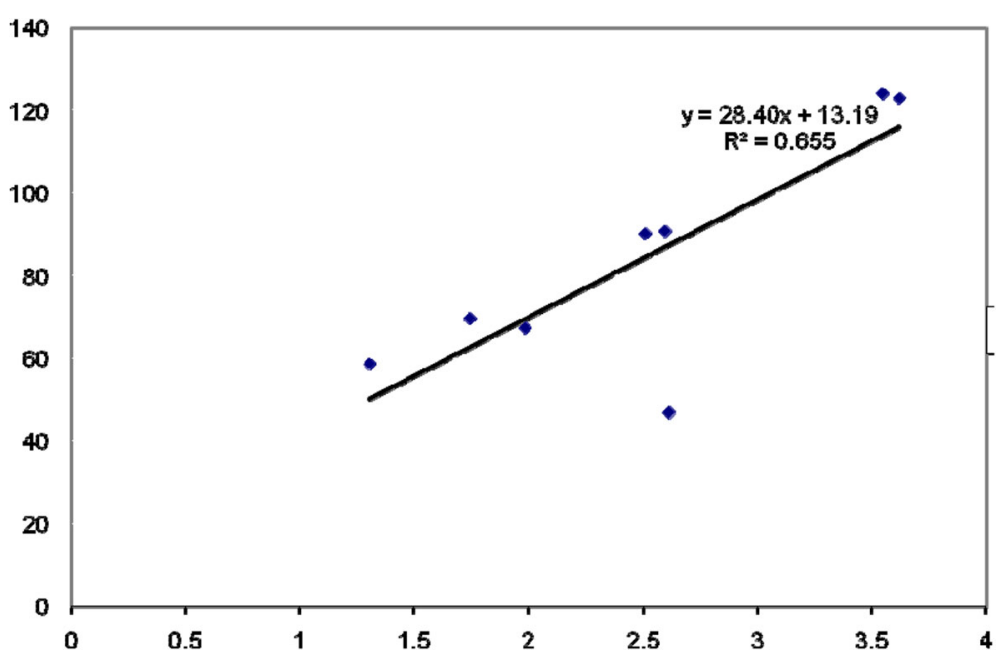

Fig. 1 LD determination curve of bee venom (13.19 mg/kg b.w.)

the experimental period (60 days) was shown to be severely affected. Inflammatory cells and vacuolation of the small pyramidal cells with altered stained nuclei of the CA1 (Fig. 4D) were noted as compared to both the control (Fig. 4A, A1) and acrylamide administration for 30 days and 45 days (Fig. 4B, C), respectively. In the chips feeding groups, time-dependent effects were also observed. Vacuolation of the small pyramidal cells, a lesser thickness of the CA1 zone, and cell detachment (Fig. 4G) were noted in chips-fed group for 60 days as compared to the groups feeding for 30 and 45 days (Fig. 4E, F) and the control group (Fig. 4A, A1), respectively. In bee venom- and bradykinin-potentiating factor-treated groups separately (Fig. 4H, I) or either with acrylamide (Fig. 4J, K) or with chips administration
(Fig. 4L, M), no histological changes were noted as those observed in either the acrylamide- or chips-administered groups at 60 days.

Immunohistochemical staining of selected groups for $\alpha$-synuclein showed its normal distribution in the control group (Fig. 5a) as a mild positive expression in small pyramidal cells of the CA1 zone of the hippocampus. The acrylamide-administrated groups showed a marked gradual elevation of expression of immunostaining of $\alpha$-synuclein. Intracellular elevation in the acrylamide-administrated group for 30 days was noted as compared to the increased level both intra- and extracellular at both 45 and 60 days of acrylamide administration (Fig. 5b-d), respectively. In chips feeding at 60 days, slightly increased expression of $\alpha$-synuclein was noted at the periphery of the pyramidal

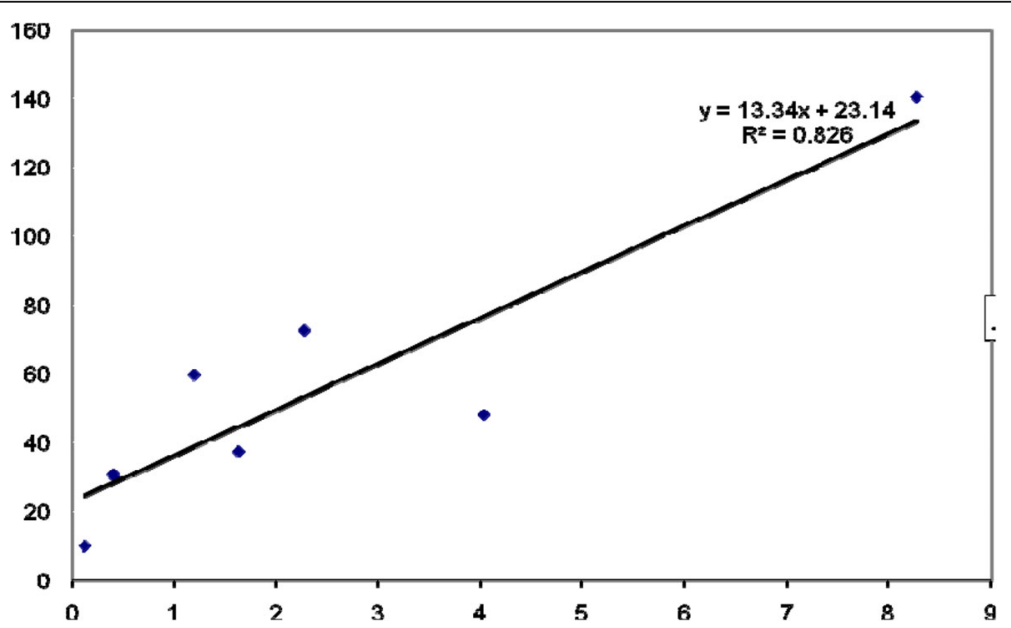

Fig. 2 LD50 determination curve of BPF (23.14 mg/kg b.w.) 

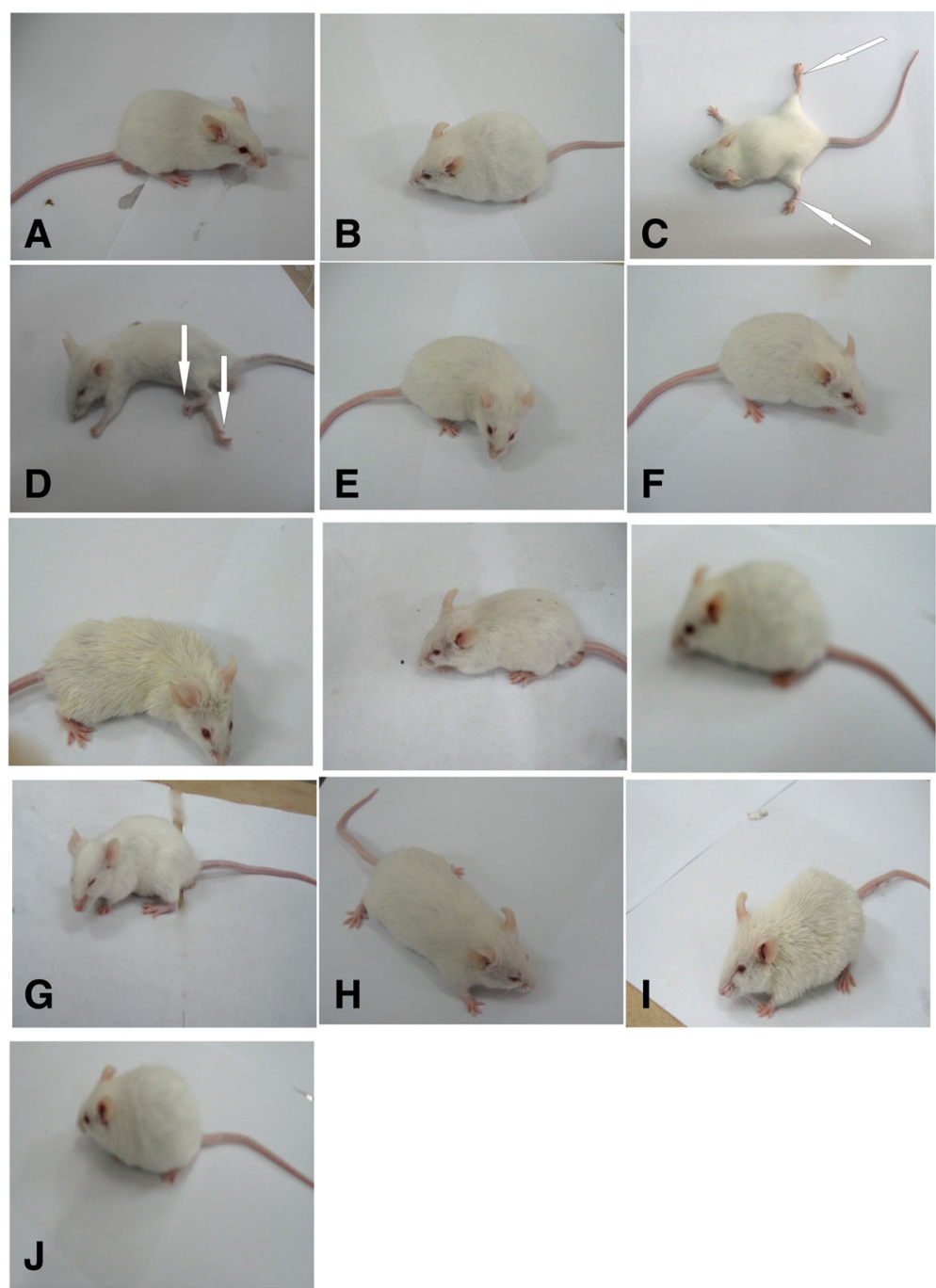

Fig. 3 Photographs showing induced weakness of limbs at 45 (c) and 60 days (d) of the acrylamide-administered group compared to the control (a) and acrylamide-administered group for 30 days (b). The chips feeding groups (e-g), bee venom group (h), and BPF- (i) treated group showed normal movement and gait. The combined groups of treatments with bee venom (j) or with BPF showed improvement in movement and gait as compared with the acrylamide-administered group $(\mathbf{k}-\mathbf{m})$. Arrows indicate dislocated limbs in acrylamide administration at 45 and 60 days

cells of the CA1 zone (Fig. 5e). In contrast, intracellular expression of $\alpha$-synuclein was not observed within the pyramidal cells in the bee venom-treated groups (Fig. 5f) as compared to both the control and acrylamide-administrated groups. The BPF group at 60 days of treatment showed a negative intracellular expression of $\alpha$-synuclein (Fig. 5g) compared to the control group. The acrylamide-administrated groups treated with either bee venom (Fig. 5h) or BPF (Fig. 5i) showed normal expression of $\alpha$-synuclein similar to control. The expression in acrylamide combined treatment is severely downregulated as compared to that observed in the acrylamide-administrated group. The chips-fed groups either with bee venom (Fig. 5j) or BPF (Fig. 5k) showed the normal expression and distribution of staining that was mostly similar to the control.

\section{Cerebellum}

Histological staining with hematoxylin and eosin of the control group demonstrated that the cerebellum region consists of two layers, an outer gray matter and an inner white matter. In the gray matter, three distinct cell layers can be distinguished. The innermost layer is the granular cell layer, the middle layer is the Purkinje cell layer, and the outer layer is the molecular layer. The Purkinje cell layer forms the border between the granular and molecular layers. The white matter consists of myelinated nerve fibers and also contains numerous neuroglia (Fig. 6A, A1). In the acrylamide-administrated groups, time-dependent effects were observed among the Purkinje cell layer of the gray matter. Degenerated cells were noted in 60 days of treatment (Fig. 6D) as 


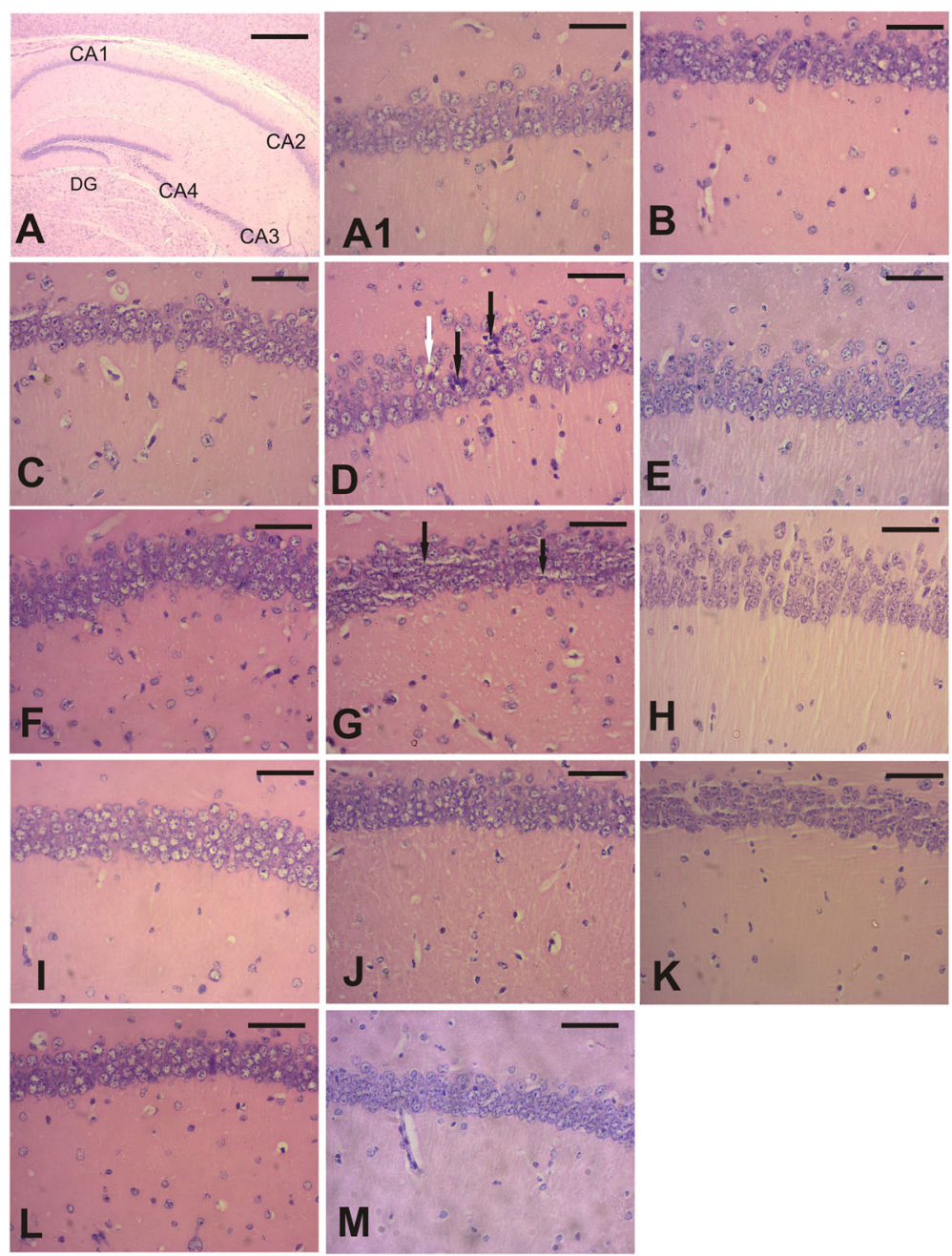

Fig. 4 Photomicrographs of stained sections of the hippocampus showing the anatomy (a) and the small pyramidal cells in the CA1 zone of the control group (A1). Inflammation cells (white arrows) and cell vacuolation (black arrow) of the CA1 zone in the acrylamide-administrated group for 60 days (d) are shown compared to the control (A1) and acrylamide administration for 30 and 45 days (b, c), respectively. Cell vacuolation of the CA1 cell zone in the chips feeding group (arrows, $\mathbf{g}$ ) is shown at 60 days compared to both 30 and 45 days (d, f) of the chips feeding group. The BV- (h) and BPF- (i) treated groups for 60 days are similar to the control group. The acrylamide-administrated groups treated either with BV (j) or with BPF (k) showed improvement as compared with the acrylamide-administrated group for 60 days. The chips feeding groups treated either with BV (I) or with BPF (m) showed improvement as compared with the chips feeding group for 60 days. H\&E stain; scale bar, A is $50 \mu m$; A1-M is $10 \mu \mathrm{m}$

compared to both the control (Fig. 6 A1) and 30 days (Fig. 6) $\mathrm{B}$ and 45 days of administration (Fig. $6 \mathrm{C}$ ), respectively. In the chips-fed groups, time-dependent effects were also observed along the experimental periods. Degeneration of the Purkinje cells was noted in the chips feeding group at 60 days (Fig. 6G) compared to the groups feeding for 30 and 45 days (Fig. 6E, F) and the control group (Fig. 6 A1), respectively. In both the bee venom- and the bradykinin-potentiating factor-treated groups (Fig. 6H, I) throughout the different periods of study, no histological changes were noted. The acrylamide-administrated groups treated with either bee venom (Fig. 6J) or bradykinin-potentiating factor (Fig. 6K) along the experimental periods showed an intact Purkinje cell layer, compared to the acrylamide-administrated group (Fig. 6D). The chips feeding groups treated with either bee venom (Fig. 4L) or bradykinin-potentiating factor (Fig. 6M) showed improvement in the defects of the Purkinje cells that were accompanied with the chips feeding group at 60 days (Fig. 6G).

Immunohistochemical staining of $\alpha$-synuclein for selected groups showed its normal distribution in the control group (Fig. 7a) as a mild positive expression in the three layers of the cerebellum region. The expression of $\alpha$-synuclein in the acrylamide-administrated groups from 30 to 60 days of administration is elevated gradually within the nucleus and the cytoplasm of the 


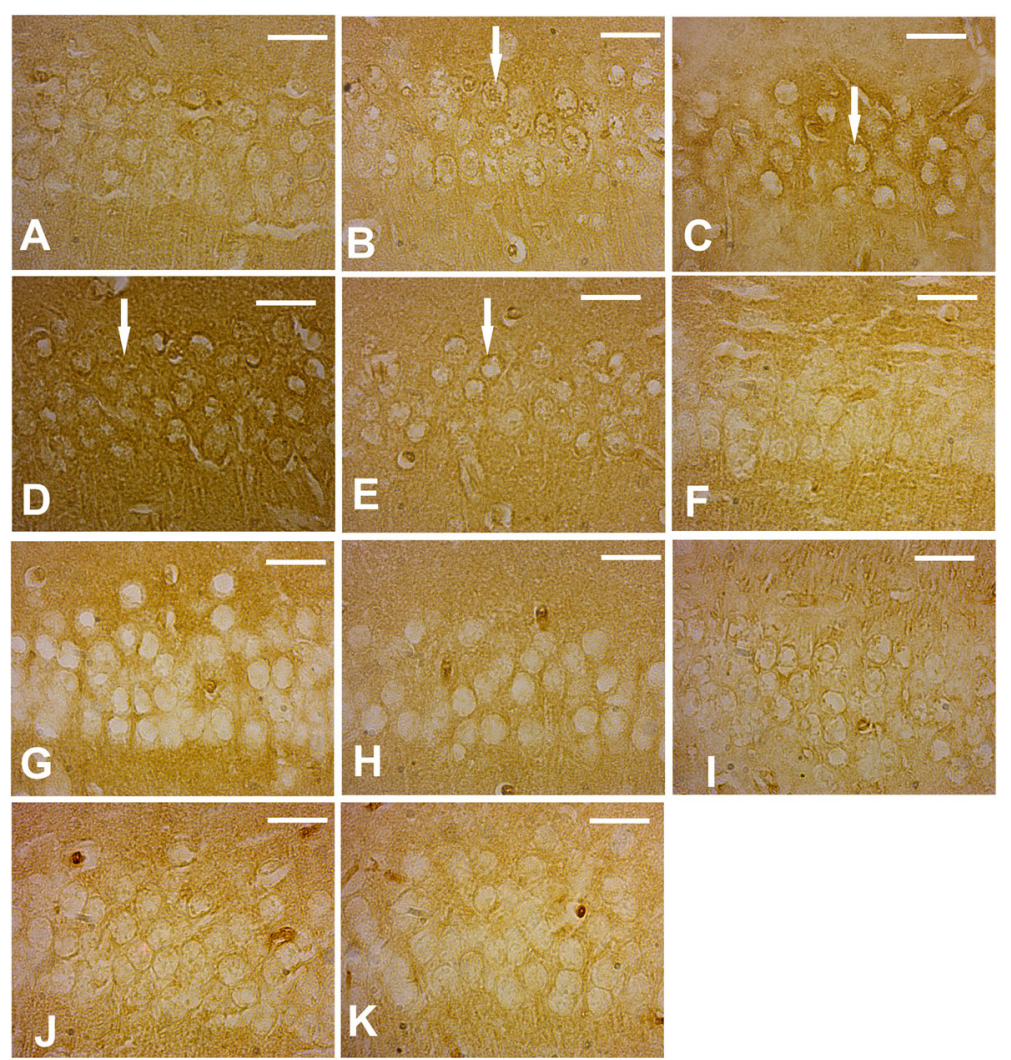

Fig. 5 Photomicrographs of immunohistochemistry of a-synuclein in the CA1 region of the hippocampus of the control group (a). The acrylamide-administrated groups showed a gradual increase in the expression from 30 to 45 days of treatment (arrows; b, c) and denser expression at 60 days (arrows, d). The chips feeding group at 60 days showed increase of intracellular expression (arrows, e). The BV- and BPF-treated groups showed nearly the same expression of the control $(\mathbf{f}, \mathbf{g})$. The acrylamide-administrated groups treated with either BV (h) or BPF (i) showed normal expression of a-synuclein similar to the control. The chips feeding groups treated with either BV (j) or BPF (k) showed the normal distribution of staining similar to the control. Immunostaining of a-synuclein; scale bar $5 \mu \mathrm{m}$

Purkinje cells and best detected at 45 (Fig. 7c) and 60 days (Fig. $7 \mathrm{~d}$ ) than at 30 days of administration (Fig. $7 \mathrm{~b})$, respectively. In the chips feeding group at 60 days, the increase of intracellular expression of $\alpha$-synuclein was noted in the Purkinje cells (Fig. 7e). In contrast, the increased expression of $\alpha$-synuclein was not observed within the Purkinje cells in bee venom-injected groups (Fig. 7f) or bradykinin-potentiating factor group (Fig. $7 \mathrm{~g}$ ) at 60 days of treatment. The acrylamide-administrated groups treated with either bee venom (Fig. $7 \mathrm{~h}$ ) or bradykinin-potentiating factor (Fig. 5i) for 60 days showed downregulated expression of $\alpha$-synuclein that returned to normal pattern compared to the acrylamide-administrated group. The chips feeding groups treated with either bee venom (Fig. 7j) or bradykinin-potentiating factor (Fig. 7k) for 60 days showed the normal expression and distribution of staining that was mostly similar to the control.

\section{Cerebral cortex}

Hematoxylin and eosin stain revealed normal neurons of the cerebral cortex that appeared with normal soma, dendrites, and nuclei in the control group (Fig. 8a). In the acrylamide-administrated groups, time-dependent effects regarding the morphological appearance of the neurons were observed. Severe shrinkage of neurons was noted in the acrylamide-administrated groups for 60 days (Fig. 8d) as compared to both the control (Fig. 8a) and 30 (Fig. 8b) and 45 (Fig. 8c) days of acrylamide administration, respectively. The chips feeding groups at 45 and 60 days showing shrunken neurons and increased inflammatory cells in the severely vacuolated background of glia (Fig. 8f, g) similar to the acrylamide-administrated groups were noted. The chips feeding group at 30 days was less affected than that at 45 and 60 days of administration and look like those of the control. In both the bee venom- and the bradykinin-potentiating factor-treated groups at 60 days (Fig. 8h, i), no histological 


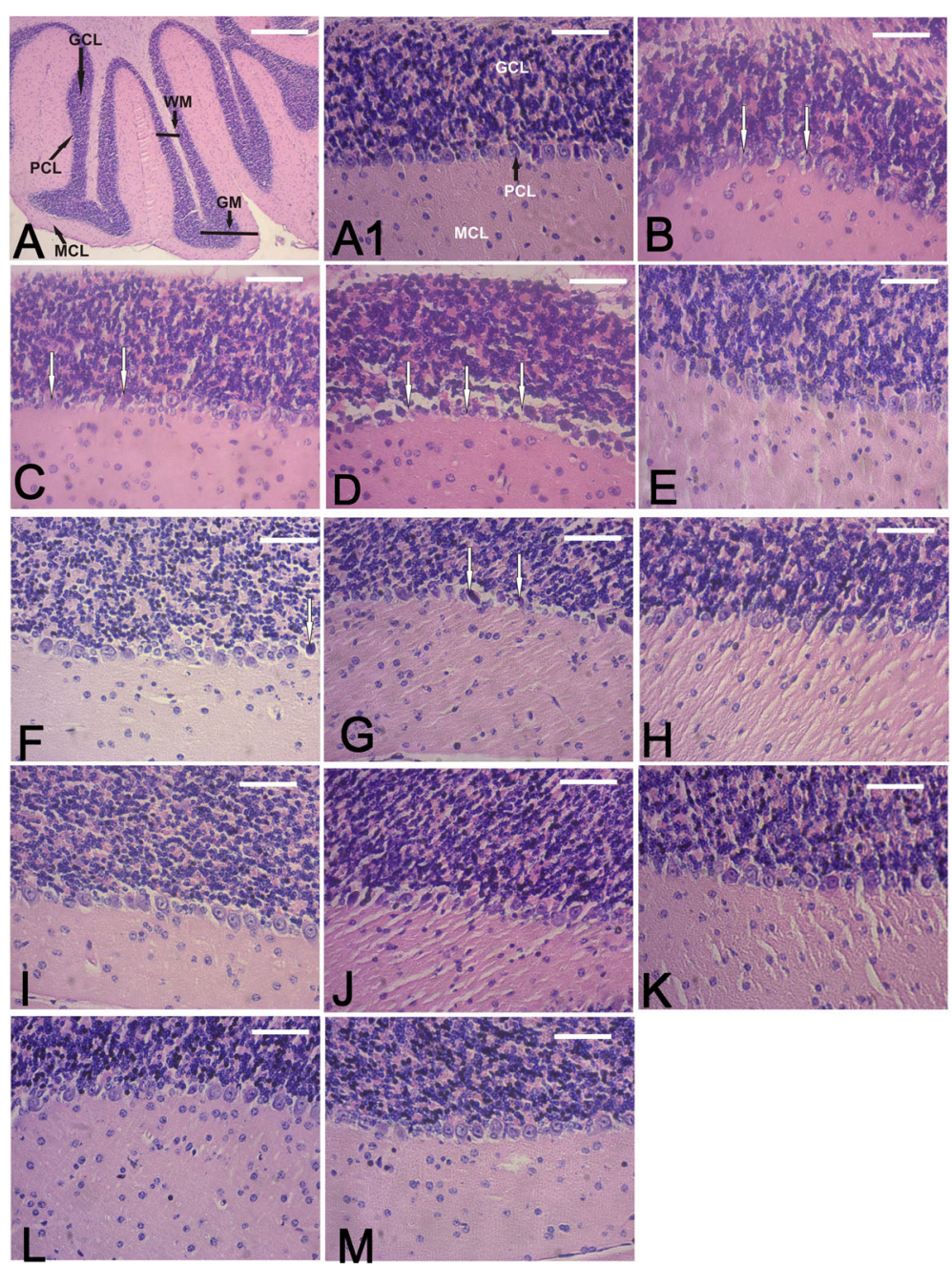

Fig. 6 Photomicrographs of the cerebellar region showing the gray (GM) and white matter (WM), granular cell layer (GCl), Purkinje cell layer (PCL), and the molecular cell layer $(\mathrm{MCl})$ of control are shown $(\mathbf{A}, \mathbf{A} \mathbf{1})$. In the acrylamide-administrated groups, degeneration of the Purkinje cell was shown at 60 days (arrows, D) compared to 30 and 45 days (arrows; B, C) and the control (A1). In the chips feeding groups, Purkinje cell degeneration was noted at 60 (arrows, G) than at $30(\mathbf{E})$ and 45 (arrows, F) days of feeding. The BV- $(\mathbf{H}$ ) and BPF-treated groups at 60 days of treatment (I) showed Purkinje cells similar to the control. The acrylamide-administrated groups treated with either BV (J) or BPF (K) showed improvement compared to degeneration which has been detected in the acrylamide group. The chips feeding groups treated with either BV (L) or BPF (M) showed improvement in Purkinje cell integrity compared to chips-induced Purkinje cell degeneration. H\&E stain; scale bar, A $50 \mu$ m; A1-M $10 \mu \mathrm{m}$

changes in the neurons were noted. The acrylamide-administrated groups treated with either bee venom (Fig. 8j) or bradykinin-potentiating factor (Fig. 8k) showed improvement in the morphological appearance of neurons, compared to the acrylamide-administrated group at 60 days. The chips feeding groups treated with either bee venom (Fig. 8l) or bradykinin-potentiating factor (Fig. 8m) showed improvement in the morphological appearance of neurons compared to the chips feeding group at 60 days.

Immunohistochemical staining of $\alpha$-synuclein for selected groups showed its normal distribution in the control group (Fig. 9a) as a mild positive expression in neurons and glia of the cerebrum region. The acrylamide-administrated groups, along the different experimental periods (Fig. 9b-d), showed marked elevation in $\alpha$-synuclein expression consistent with the expression in both the hippocampus and cerebellum. In the chips feeding group at 60 days, increased expression of $\alpha$-synuclein was noted in neurons (Fig. 9e). In contrast, the bee venom-injected group (Fig. 9f) and bradykinin-potentiating factor treated-group (Fig. 9g) at 60 days showed $\alpha$-synuclein expression similar to the control. The acrylamide-administrated groups treated with either bee venom (Fig. 9h) or bradykinin-potentiating factor (Fig. 9i) at 60 days showed a downregulation of $\alpha$-synuclein compared to the acrylamide- 

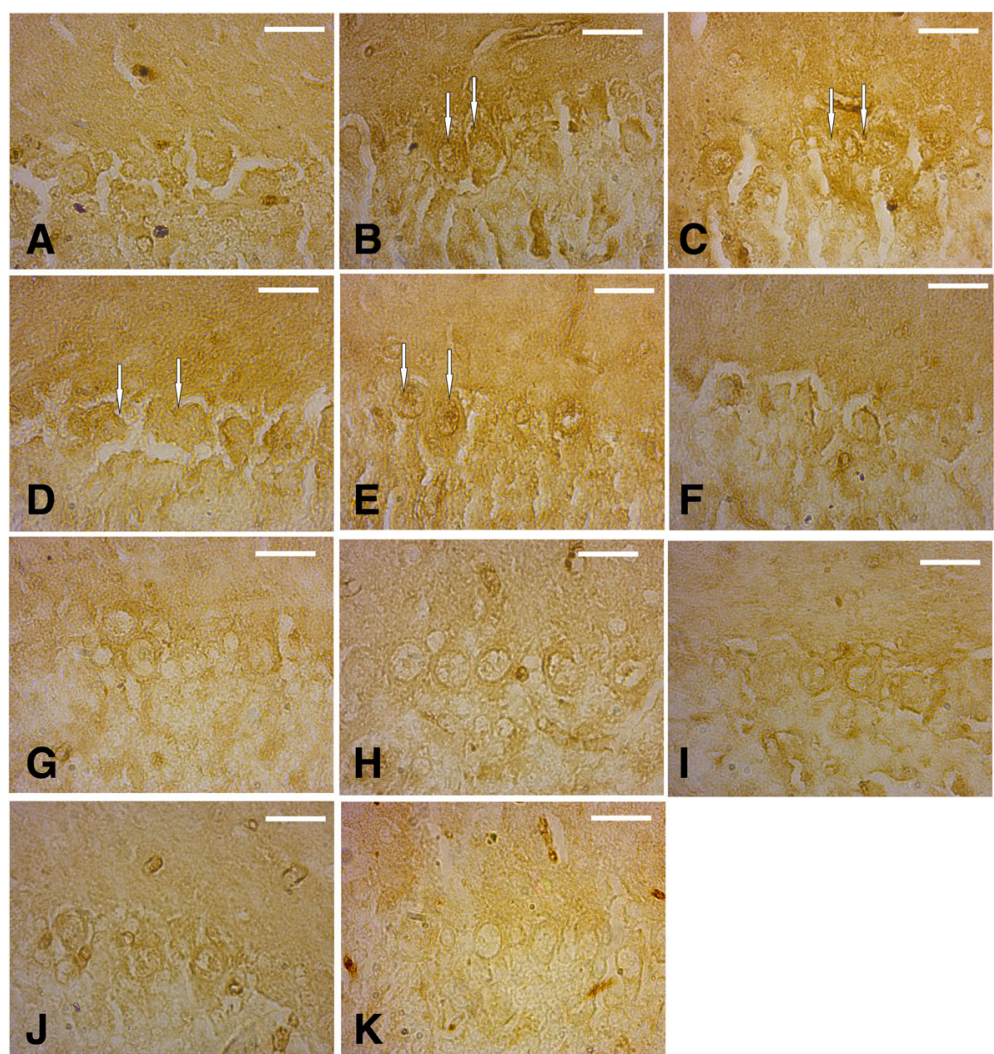

Fig. 7 Photomicrographs of immunohistochemistry of a-synuclein in the cerebellar region of the control group (a). The acrylamide-administrated groups showed a gradual increase in expression from 30 days (arrows, b) and 45 days (arrows, c) and denser in 60 days of administration (arrows, d). The chips feeding group showed increase of intracellular expression (arrows, e). The BV- and BPF-treated groups showed nearly the same expression of the control $(\mathbf{f}, \mathbf{g})$. The acrylamide-administrated groups treated with either BV (h) or BPF (i) showing downregulated expression of a-synuclein expression compared to acrylamide-induced overexpression. The chips feeding groups treated with either BV (j) or BPF (k) showed the normal expression and distribution of staining similar to the control. Immunostaining of a-synuclein; scale bar $5 \mu \mathrm{m}$

administrated group at 60 days. The chips feeding groups treated with either bee venom (Fig. 9j) or bradykinin-potentiating factor (Fig. 9k) showed also downregulated expression in both the neurons and the glia compared to the expression in the chips feeding groups.

\section{Discussion}

In the present study, abnormal neurobehavioral and morphological changes were recorded in mice treated with acrylamide. The changes include hind limb dysfunction, abnormal gait, ataxia, increased landing of the limbs, weakness of the muscles, and general emaciation. These changes are consistent with the neuronal atrophy of the studied regions of the brain in the acrylamide-administered groups in a time-dependent manner. The results coincide with those reported in other investigations concerning acrylamide neurotoxicity (AL-Mosaibih, 2013; El-Bohi, Moustafa, El sharkawi, \& Sabik, 2011; Shukla et al., 2002) similar to those observed in the present investigation that led to dysfunction of limbs and abnormal behavior. Acrylamide has been proved to induce a central and peripheral neuropathy in laboratory animals including rats and monkeys as well as in humans (Lehning et al., 2003 a, b; LoPachin, 2004; Seale, Feng, Agarwal, \& El-Alfy, 2012). Furthermore, acrylamide induces neuropathy and neuronal loss which leads to behavioral abnormalities in early development (Crofton et al., 1996; El-Bakry, Abdul-Hamid, \& Allam, 2013; Lehning, Balaban, Ross, \& LoPachin, 2002a; Lehning, Balaban, Ross, Reid, \& LoPachin, 2002b). Also, acrylamide consumption impairs motor coordination and motor control and reduces motor neurons' ability to generate action potentials (Guo, Li, \& Xiao, 2010; Wise, Gordon, Soper, Duchai, \& Morrissey, 1995). A low dose of acrylamide in the drinking water revealed focal gliosis, and a high dose of acrylamide showed lesions with severe diffuse gliosis and causes progressive degeneration of Purkinje cell dendrites in the cerebellar cortex (Eman \& Amany, 2008; Lehning et al. 2002 a, b). In high doses of acrylamide (15 and $30 \mathrm{mg} / \mathrm{kg}$ ), neuron abnormalities such as increased concentrated nuclei, darkly stained basophilic chromatin, small cell bodies, absent nucleoli, and dopaminergic system alterations were reported (Agrawal \& 


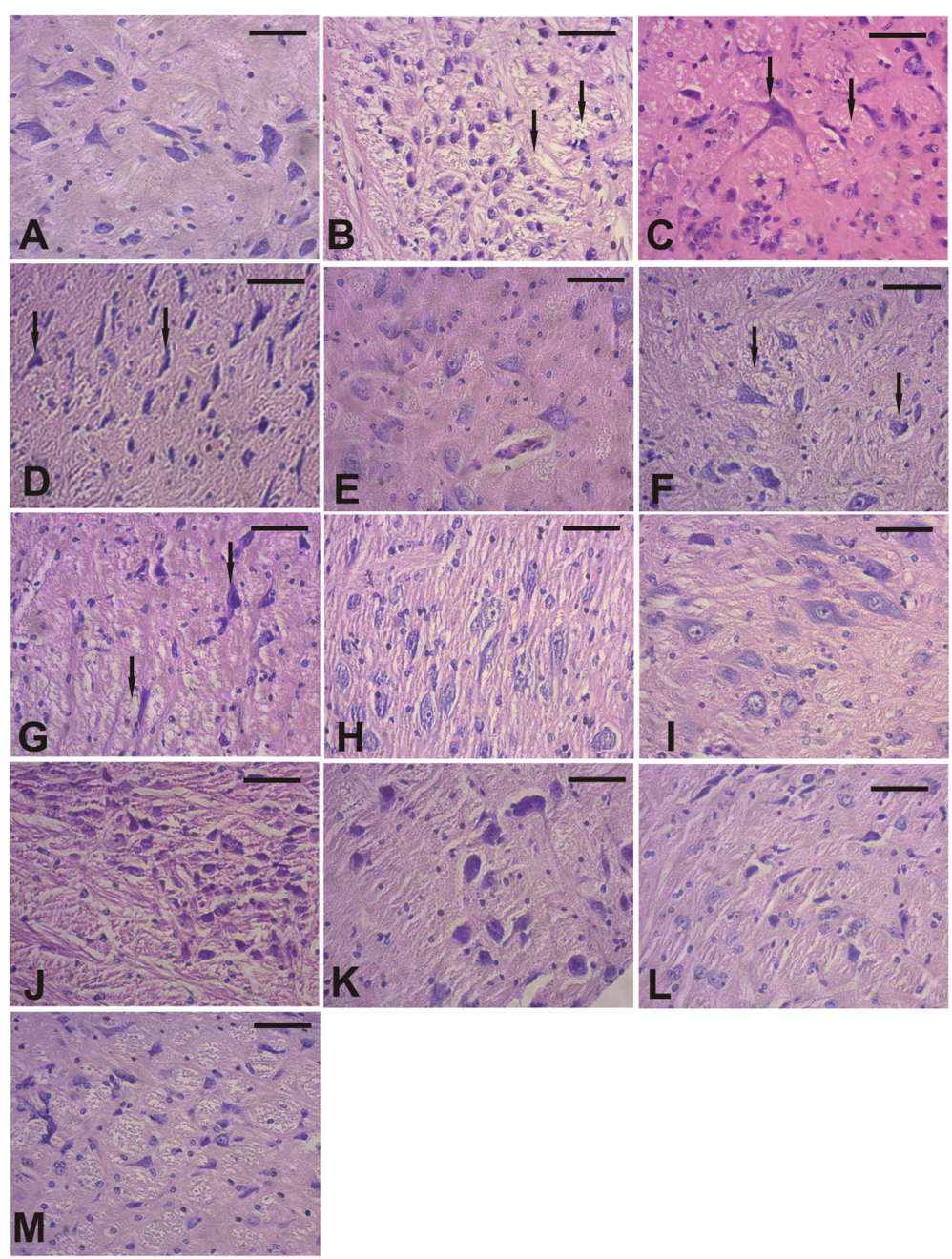

Fig. 8 Photomicrographs of the cerebral cortex showing neurons of the control group (a). The acrylamide-administrated groups at 30 days (arrows, b), 45 days (arrows, c), and 60 days (arrows, d) showing gradual shrinkage of neurons. The chips feeding groups at 30 days (e), 45 days (arrows, f), and 60 days (arrows, $\mathbf{g}$ ) showing also the gradual neuronal shrinkage and glial vacuolation. The BV- and BPF-treated groups at 60 days (h, i) showing similarity to the control. The acrylamide-administrated groups treated with either BV or BPF showing recovery (j, $\mathbf{k})$. The chips feeding groups treated with either BV or BPF showing recovery $(\mathbf{I}, \mathbf{m})$. H\&E stain; scale bar $10 \mu \mathrm{m}$

Squibb, 1981; Tian et al., 2015). The mechanism underlying acrylamide-induced neuronal injury related to acrylamideinduced apoptosis through elevated expression of apoptotic markers as indicated with bcl2 and Bax (Li, Jiang, \& Cui, 2008) in the cerebral cortex of rats. In the present investigation, cell vacuolation, inflammatory cell infiltration, Purkinje cell degeneration, and neuronal shrinkage with concomitant elevation of $\alpha$-synuclein in the studied regions of the brain were noted. These effects were clarified in a time-dependent manner in either the acrylamide- or chips-administered groups compared to the control. Thus, acrylamide of chemical source or of carbohydrate-rich foods processing at elevated temperatures induces cell dysfunction and degeneration of neuronal cells through elevated $\alpha$-synuclein resulting in limb dysfunction and movement arrest as observed at the morphological, histological, and immunohistochemical levels of the present investigation.

From the other side, several researches aimed to find appropriate therapeutics to alleviate acrylamide toxicity and to prevent potential neuronal damages. In this regard, many compounds from a variety of plants, vitamins, and chemicals have been tested and proved to ameliorate the acrylamide toxicity. Extraction of Panax ginseng, Acorus calamus, linalool, grape leaves, garlic, curcumin, and selenium was investigated (Cao, Liu, Jia, et al., 2008; Mannaa, Abdel-Wahhab, Ahmed, \& Park, 2006; Mehri, Meshki, \& Hosseinzadeh, 2014; Osman, Romeilah, Elgammal, Ramis, \& Hasan, 2015; Prasad \& Muralidhara, 2014; Shukla et al., 2002; Taha, Korshom, Mandour, \& Sadek, 2013; Teodor, Cuciureanu, Slencu, Zamosteanu, \& Cuciureanu, 2011). The present investigation clarified the ameliorated effect of bee 

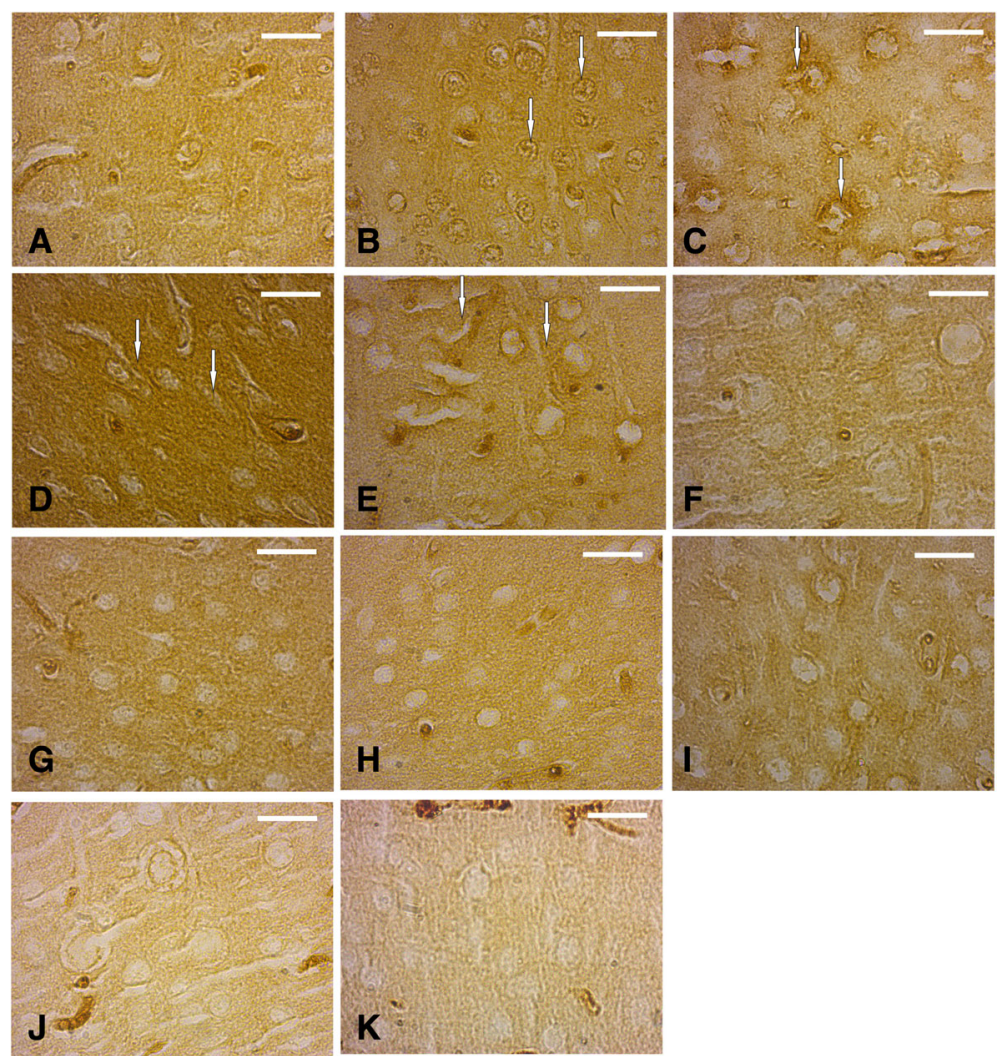

Fig. 9 Photomicrographs of immunohistochemistry of a-synuclein in neurons and the glia of the cerebral cortex of the control group (a). The acrylamide-administrated groups showed increase in expression at 30 and 45 days and more denser at 60 days of administration (arrows, b-d), respectively. The chips feeding group (arrows, e) showed increased expression of a-synuclein. The BV- and BPF-treated groups (f, $\mathbf{g}$ ) at 60 days showed a-synuclein expression similar to the control. The acrylamide-administrated groups treated with either BV (h) or BPF (i) showing downregulated expression of a-synuclein compared to acrylamide administration. The chips feeding groups treated with either BV (j) or BPF (k) showing the normal expression and distribution of staining that was mostly similar to the control. Immunostaining of a-synuclein; scale bar $5 \mu m$

venom against neurotoxicity induced by acrylamide as indicated in neuronal integrity, and suppressed $\alpha$-synuclein expression in co-administrated animals with acrylamide or chips administration results in efficient limb movement at morphological level of observation. BV was reported as a potential therapeutic agent for anti-neuroinflammatory effects in an animal model of amyotrophic lateral sclerosis and alleviated mitochondrial disruption in symptomatic hSOD 1G93A transgenic mice and multiple sclerosis (Castro et al., 2005; Nam et al., 2003; Yang et al., 2010). Bee venom also provides sustained protection against the mouse model that mimics the chronic degenerative process of Parkinson's disease (Alvarez-Fischer et al., 2013; Kim et al., 2011; Yoon \& Lee, 2013). The protective effect of bee venom was attributed to its melittin, a small peptide which represents 40 to $60 \%$ of dry whole honeybee venom which has several interesting pharmacological properties as a result of its interaction with negatively charged phospholipids and inhibits the activity of the $\mathrm{Na} / \mathrm{K}$-ATPase (Lopina, 2001). Additionally, melittin could improve motor activity and protection of dopaminergic neurons and decrease neuroinflammation in mice model (Yang et al., 2010).

In addition, the present data showed the amelioration effect of bradykinin-potentiating factor (BPF) isolated from bee venom against neurotoxicity that is induced by acrylamide or chips administration. Suppressed neurodegeneration in the brain tissues under investigation and decreased $\alpha$-synuclein expression similar to those observed in bee venom co-administration with either acrylamide or chips were observed. Bradykinin protects against brain microvascular endothelial cell death induced by pathophysiological stimuli (Bovenzi et al., 2010). In the same context, bradykinin postconditioning induces protection against ischemic brain injury and promotes neuronal survival (Danielisová, Gottlieb, Némethová, \& Burda, 2008). In addition, bradykinin has anti-inflammatory and neuroprotective effects in the central nervous system by modulating microglial function. In cultured microglia, bradykinin inhibits lipopolysaccharide (LPS)-induced tumor necrosis factor-alpha (TNF-a) (Noda et al., 2007). The protective role of 
bradykinin in general was reported in different tissues including cardiac ischemia (Pinto et al., 2000) and renal system (Bascands, Schanstra, Couture, \& Girolami, 2003) and liver damage (Sancho-Bru et al., 2007).

\section{Conclusions}

The present study was conducted to evaluate the effect of acrylamide of chemical source and of carbohydraterich foods processing at elevated temperatures on the nerve cells at different brain regions and, from the other side, to evaluate the ameliorative role of bee venom and its extracted bradykinin-potentiating factor on the degenerative effects induced by acrylamide. From the presented data, it is obvious that either the bee venom or its bradykinin extract ameliorates the degenerative effects and suppresses the expression of $\alpha$-synuclein in different brain regions under investigation. The ameliorative effects at both histological and immunohistochemical levels result in coordinated movement of co-administrated animals with acrylamide and bee venom or its bradykinin-potentiating factor. The study recommended to consider both BV and BPF as therapeutic agents in the neurodegenerative diseases in which $\alpha$-synuclein plays the effective role as Parkinson's disease.

\section{Abbreviations}

BPF: Bradykinin-potentiating factor; BV: Bee venom; H\&E: Hematoxylin and eosin stain; TNF-a: Tumor necrosis factor-alpha

\section{Availability of data and materials}

The datasets generated and analyzed during the current study are available from the corresponding author on reasonable request.

\section{Authors' contributions}

All authors suggested the study, participated in its design and coordination, interpreted the results, and approved the final manuscript.

\section{Ethics approval}

This study was approved by the Social Science Ethical Committee of the Faculty of Science, Tanta University, and complied with the Egyptian Code of Conduct for Scientific Practice, National Research Centre, Egypt.

\section{Consent for publication}

Not applicable.

\section{Competing interests}

The authors declare that they have no competing interests.

\section{Publisher's Note}

Springer Nature remains neutral with regard to jurisdictional claims in published maps and institutional affiliations.

Received: 21 June 2018 Accepted: 18 September 2018 Published online: 29 September 2018

\section{References}

Abd-El-Rahim, S. A. (1995). Effect of extracted crude venom of the jelly-fish, Eutonina indicans on kidney function. J. Egypt. Ger. Soc. Zool., 18(A), 131-147. Agrawal, A. K., \& Squibb, R. E. (1981). Effects of acrylamide given during gestation on dopamine receptor binding in rat pups. Toxicology Letters, 7, 233-238.

AL-Mosaibih, M. A. (2013). Effects of monosodium glutamate and acrylamide on the liver tissue of adult Wistar rats. Life Science Journal, 10(2s), 2013, 36-42.
Alvarez-Fischer, D., Noelker, C., Vulinović, F., Grü newald, A., Chevarin, C., Klein, C., ... Hartmann, A. (2013). Bee venom and its component apamin as neuroprotective agents in a Parkinson disease mouse model. PLoS One, 8(4), e61700.

Ashoor, S. H., \& Zent, J. B. (1984). Maillard browning of common amino acids and sugars. Journal of Food Science, 49, 1206-1207.

Bascands, J. L., Schanstra, J. P., Couture, R., \& Girolami, J. P. (2003). Bradykinin receptors: Towards new pathophysiological roles. Medical Science (Paris), 19, 1093-1100.

Bovenzi, V., Savard, M., Morin, J., Cuerrier, C. M., Grandbois, M., \& Gobeil, F. J. (2010). Bradykinin protects against brain microvascular endothelial cell death induced by pathophysiological stimuli. Journal of Cellular Physiology, 222(1), 168-176.

Buchlowalow, B. I., \& Bocker, W. (2010). Immunohistochemistry. Basics and methods. Berlin, Heidelberg: Springer Verlag.

Cao, J., Liu, Y., Jia, L., et al. (2008). Curcumin attenuates acrylamide-induced cytotoxicity and genotoxicity in HepG2 cells by ROS scavenging. Journal of Agricultural and Food Chemistry, 56(12), 059-12,063.

Castro, H. J., Mendez-Lnocencio, J. I., Omidvar, B., Omidvar, J., Santilli, J., Nielsen, H. S., ... Bellanti, J. A. (2005). A phase I study of the safety of honeybee venom extract as a possible treatment for patients with progressive forms of multiple sclerosis. Allergy and Asthma Proceedings, 26, 470-476.

Chen, J., \& Lariviere, W. R. (2010). The nociceptive and anti-nociceptive effects of bee venom injection and therapy: A double-edged sword. Progress in Neurobiology, 92, 151-183.

Chen, T., Zhou, M., Gagliardo, R., Walker, B., \& Shaw, C. (2006). Elements of the granular gland peptidome and transcriptome persist in air-dried skin of the South American orange-legged leaf frog, Phyllomedusa hypochondrialis. Peptides, 27, 2129-2136

Conlon, J. M., Jouenne, T., Cosette, P., Cosquer, D., Vaudry, H., Taylor, C. K., et al. (2005). Bradykinin-related peptides and tryptophyllins in the skin secretions of the most primitive extant frog, Ascaphus truei. General and Comparative Endocrinology, 143, 193-199.

Crofton, K. M., Padilla, S., Tilson, H. A., Anthony, D. C., Raymer, J. H., \& MacPhail, R. C. (1996). The impact of dose rate on the neurotoxicity of acrylamide, the interaction of administered dose, target tissue concentrations, tissue damage, and functional effects. Toxicology and Applied Pharmacol., 139, 163-176.

Danielisová, V., Gottlieb, M., Némethová, M., \& Burda, J. (2008). Effects of bradykinin postconditioning on endogenous antioxidant enzyme activity after transient forebrain ischemia in rat. Neurochemical Research, 33(6), 1057-1064.

Drury, R., \& Wallington, E. (1976). Carleton's histological technique, (pp. 48-58). London: Oxford University Press.

El-Bakry, A. M., Abdul-Hamid, M., \& Allam, A. (2013). Prenatal and perinatal exposure of acrylamide disrupts the development of spinal cord in rats. World Journal of Neuroscience, 3, 17-31.

El-Bohi, K. M., Moustafa, G. G., El sharkawi, N. I., \& Sabik, L. M. (2011). Genotoxic effects of acrylamide in adult male albino rats liver. Journal of American Science, 7(1), 1097-1108.

Eman, M. A. E., \& Amany, Y. M. R. (2008). Some studies on acrylamide intoxication in male albino rats. Egyptian Journal of Comparative Pathology and Clinical Pathology, 21, 222-245.

Eriksson, S. (2005). Acrylamide in food products: Identification, formation and analytical methodology, PhD thesis. Stockholm: Department of Environmental Chemistry, Stockholm University.

Ferreira, L. A., Alves, E. W., \& Henriques, O. B. (1993). Peptide T, a novel bradykinin potentiator isolated from Tityus serrulatus scorpion venom. Toxicon, 31(8), 941-947.

Ferreira, L. A. F., Mollring, T., Lebrun, F. L. A. S., Raida, M., Znottka, R., \& Habermehl, G. G. (1995). Structure and effects of a kinin potentiating fraction F (AppF) isolated from Agkistrodon piscivorus venom. Toxicon, 33, 1313-1319.

Ferreira, S. H. (1965). A bradykinin-potentiating factor (Bpf) present in the venom of Bothrops jararaca. British Journal of Pharmacology, 24, 163-169.

Ferreira, S. H., Bartelt, D. C., \& Greene, L. J. (1970). Isolation of bradykinin potentiating peptides from Bothrops jararaca venom. The Biochemist, 9(13), 2583-2593.

Gajski, G., \& and Garaj-Vrhovac, V. (2009). Radioprotective effects of honey bee venom (Apis mellifera) against 915-MHz microwave radiation induced DNA damage in Wistar rat lymphocytes: In vitro study. International Journal of Toxicology; 28(2): 88-98.

Guo, C., Li, B., \& Xiao, J. (2010). General survey of mechanisms of acrylamide neurotoxicity. Journal of Hygiene Research, 39, 282-285. 
Hodgson, W. C., \& Isbister, G. K. (2009). The application of toxins and venoms to cardiovascular drug discovery. Current Opinion in Pharmacology, 9, 173-176.

Hoffman, D. R. (2006). Hymenoptera venom allergens. Clinical Reviews in Allergy and Immunology, 30, 109-128.

Johnson, K. A., Gorzinski, S. J., Bodner, K. M., Campbell, R. A., Wolf, C. H., Friedman, M. A., \& Mast, R. W. (1986). Chronic toxicity and oncogenicity study on acrylamide incorporated in the drinking water of Fischer 344 rats. Toxicology and Applied Pharmacology, 85, 154-168.

Khalil, W. K. B., Assaf, N., ElShebiney, S. A., \& Salem, N. A. (2015). Neuroprotective effects of bee venom acupuncture therapy against rotenone-induced oxidative stress and apoptosis. Neurochemistry International, 80, 79-86.

Kim, B. Y., \& Jin, B. R. (2016). Molecular characterization of a venomacid phosphatase from the Asiatic honeybee Apis cerana. Journal of Asia-Pacific Entomology, 19, 793-797.

Kim, J., Yang, E. J., Lee, M., Kim, Y., Huh, Y., et al. (2011). Bee venom reduces neuroinflammation in the MPTP-induced model of Parkinson's disease. The International Journal of Neuroscience, 121, 209-217.

Konno, K., Palma, M. S., Hitara, I. Y., Juliano, M. A., Juliano, L., \& Yasuhara, T. (2002). Identification of bradykinins in solitary wasp venoms. Toxicon, 40, 309-312.

Kwon, Y. B., Lee, J. H., Han, H. J., Mar, W. C., Lee, H. J., Yang, I. S., et al. (2001). Bee venom pretreatment has both an antinociceptive and anti-inflammatory effect on carrageenan-induced inflammation. The Journal of Veterinary Medical Science, 63, 251-259.

Lehning, E. J., Balaban, C. D., Ross, J. F., \& LoPachin, R. M. (2002a). Acrylamide neuropathy: II. Spatiotemporal characteristics of nerve cell damage in rat brainstem and spinal cord. Neurotoxicology, 23(3), 415-429.

Lehning, E. J., Balaban, C. D., Ross, J. F., \& LoPachin, R. M. (2003a). Acrylamide neuropathy, II. Spatiotemporal characteristics of nerve cell damage in brainstem and spinal cord. Neurotoxicology, 24, 109-123.

Lehning, E. J., Balaban, C. D., Ross, J. F., \& LoPachin, R. M. (2003b). Acrylamide neuropathy, III. Spatiotemporal characteristics of nerve cell damage in forebrain. Neurotoxicol, 24, 125-136.

Lehning, E. J., Balaban, C. D., Ross, J. F., Reid, M. L., \& LoPachin, R. M. (2002b). Acrylamide neuropathy: I. Spatiotemporal characteristics of nerve cell damage in rat cerebellum. Neurotoxicology, 23(3), 397-414.

Li, S., Jiang, H., \& Cui, N. (2008). Effects of bcl-2 and bax expression and neuronal denegreation in the cerebral cortex in rats with acrylamide treatment. $J$. Toxicol., 1, 31-32.

LoPachin, R. M. (2004). The changing view of acrylamide neurotoxicity. Neurotoxicology, 25, 617-630.

LoPachin, R. M., Schwarcz, A. I., Gaughan, C. L., Mansukhani, S., \& Das, S. (2003). In vivo and in vitro effects of acrylamide on synaptosomal neurotransmitter uptake and release. Neurotoxicology, 25, 349-363.

Lopina, O. D. (2001). Interaction of Na, K ATPase catalytic subunit with cellular proteins and other endogenous regulators. Biochemistry (Mosc), 66, 1122-1131.

Mannaa, F., Abdel-Wahhab, M. A., Ahmed, H. H., \& Park, M. H. (2006). Protective role of Panax ginseng extract standardized with ginsenoside Rg3 against acrylamideinduced neurotoxicity in rats. Journal of Applied Toxicology, 26(3), 198-206.

Mehri, S., Meshki, M. A., \& Hosseinzadeh, H. (2014). Linalool as a neuroprotective agent against acrylamide-induced neurotoxicity in Wistar rats. Drug and Chemical Toxicology, 38(2), 1-5.

Meier, J., \& Theakston, R. D. (1986). Approximate LD50 determinations of snake venoms using eight to ten experimental animals. Toxicon, 24(4), 395-401.

Meki, A. R., Nassar, A. Y., \& Rochat, H. (1995). A bradykinin-potentiating peptide (peptide K12) isolated from the venom of Egyptian scorpion Buthus occitanus. Peptides, 16(8), 1359-1365.

Nam, K. W., Je, K. H., Lee, J. H., Han, H. J., Lee, H. J., Kang, S. K., \& Mar, W. (2003). Inhibition of COX-2 activity and proinflammatory cytokines (TNF-alpha and IL-1 beta) production by water-soluble sub-fractionated parts from bee (Apis mellifera) venom. Archives of Pharmacal Research, 26, 383-388.

Noda, M., Kariura, Y., Pannasch, U., Nishikawa, K., Wang, L., Seike, T., ... Wada, K. (2007). Neuroprotective role of bradykinin because of the attenuation of proinflammatory cytokine release from activated microglia. Journal of Neurochemistry, 101, 397-410.

Orśolić, N. (2012). Bee venom in cancer therapy. Cancer Metastasis Reviews, 31, 173-194.

Osman, M. A., Romeilah, R. M., Elgammal, M. H., Ramis, E. S., \& Hasan, R. S. (2015). Subchronic toxicity of acrylamide in fried rice and preventive effect of grape leaves. Asian Journal of Biochemistry, 11(2), 68-81.

Ozdemir, C., Kucuksezer, U. C., Akdis, M., \& Akdis, C. A. (2011). Mechanisms of immunotherapy to wasp and bee venom. Clinical and Experimental Allergy, $41,1226-1234$.
Peiren, N., de Graaf, D. C., Vanrobaeys, F., Danneels, E. L., Devreese, B., Van Beeumen, J., \& Jacobs, F. J. (2008). Proteomic analysis of the honey bee worker venom gland focusing on the mechanisms of protection against tissue damage. Toxicon, 52, 72-83.

Pinto, Y. M., Bader, M., Pesquero, J. B., Tschope, C., Scholtens, E., van Gilst, W. H., \& Buikema, H. (2000). Increased kallikrein expression protects against cardiac ischemia. The FASEB Journal, 14, 1861-1863.

Prasad, S. N., \& Muralidhara (2014). Neuroprotective effect of geraniol and curcumin in an acrylamide model of neurotoxicity in Drosophila melanogaster: Relevance to neuropathy. Journal of Insect Physiology, 60, 7-16.

Rittschof, D., \& Cohen, J. H. (2004). Crustacean peptide and peptide-like pheromones and kairomones. Peptides, 25, 1503-1516.

Roberts, R. A. (1989). Bradykinin receptors: Characterization, distribution and mechanisms of signal transduction. Progress in Growth Factor Research, 1, 237-252.

Sancho-Bru, P., Bataller, R., Fernandez-Varo, G., Moreno, M., Ramalho, L. N., Colmenero, J., ... Gines, P. (2007). Bradykinin attenuates hepatocellular damage and fibrosis in rats with chronic liver injury. Gastroenterologia, 133(6), 2019-2028.

Seale, S. M., Feng, Q., Agarwal, A. K., \& El-Alfy, A. T. (2012). Neurobehavioral and transcriptional effects of acrylamide in juvenile rats. Pharmacology, Biochemistry, and Behavior, 101, 77-84.

Shukla, P. K., Khanna, V. K., Ali, M. M., Maurya, R. R., Handa, S. S., \& Srimal, R. C. (2002). Protective effect of Acorus calamus against acrylamide induced neurotoxicity. Phytotherapy Research, 16, 256-260.

Smith, E. A., \& Oehme, F. W. (1991). Acrylamide and polyacrylamide: A review of production, use, environmental fate and neurotoxicity. Reviews on Environmental Health, 9, 215-228.

Son, J. W., Lee, Y. H., Lee, S. H., Song, C. K., \& Lee, J. T. H. (2007). Therapeutic application of anti arthritis, pain-releasing and anti cancer effects of bee venom and its constituent compounds. Pharmacology \& Therapeutics, 115, 361-763.

Taha, N., Korshom, M., Mandour, A., \& Sadek, K. (2013). Effects of garlic and acrylamide on some antioxidant enzymes. Global J. of Medic. Plant Resear., 1(2), 190-194.

Tareke, E., Rydberg, P., Karlsson, P., Eriksson, S., \& Törnqvist, M. (2002). Analysis of acrylamide, a carcinogen formed in heated foodstuffs. J. of Agricult. and Food Chemist., 50, 4998-5006.

Teodor, V., Cuciureanu, M., Slencu, B., Zamosteanu, N., \& Cuciureanu, R. (2011). Potential protective role of selenium in acrylamide intoxication. A biochemical study. Studia Universitatis "Vasile Goldiş", Seria Ştiințele Vieții, 21(2), 263-268.

Tian, S. M., Ma, Y. X., Shi, J., Lou, T. Y., Liu, S. S., \& Li, G. Y. (2015). Acrylamide neurotoxicity on the cerebrum of weaning rats. Neural Regeneration Research, 10(6), 938-943.

Torfs, P., Nieto, J., Veelaert, D., Boon, D., van de Water, G., Waelkens, E., et al. (1999). The kinin peptide family in invertebrates. Annals of the New York Academy of Sciences, 897, 361-373.

Törnqvist, M. (2005). Acrylamide in food: The discovery and its implications. In Chemistry and Safety of Acrylamide in Food, See Friedman \& Mottram, (pp. 1-19).

Wise, L. D., Gordon, L. R., Soper, K. A., Duchai, D. M., \& Morrissey, R. E. (1995). Developmental neurotoxicity evaluation of acrylamide in Sprague-Dawley rats. Neurotoxicology and Teratology, 17, 189-198.

Yang, J., Jiang, J. H., Lee, S. M., Yang, S. C., Hwang, H. S., Lee, M. S., \& Choi, S. M. (2010). Bee venom attenuates neuroinflammatory events and extends survival in amyotrophic lateral sclerosis models. Journal of Neuroinflammation, 7, 69.

Yeow, C., \& Kini, R. M. (2012). Toxicon from snake venom toxins to therapeutics-cardiovascular examples. Toxicon, 59, 497-506.

Yoon, M., \& Lee, D. (2013). Investigation of the neuroprotective effects of beevenom acupuncture in a mouse model of Parkinson's disease by using immunohistochemistry and in-vivo $1 \mathrm{H}$ magnetic resonance spectroscopy at 9.4 T. Journal of the Korean Physical Society, 62(2), 320-327.

Zhang, Y., Zhang, G., \& Zhang, Y. (2005). Occurrence and analytical methods of acrylamide in heat-treated foods. Review and recent developments, J. Chromatogr, 1075, 1-21. 